Recherches en didactique des langues et des cultures

Les cahiers de l'Acedle

18-1 | 2021

En quoi les langues ont-elles un rôle à jouer dans les sociétés mondialisées au sein d'une Europe fragilisée ?

\title{
Questions de socialisation et d'identité : l'appropriation des langues dans une Europe « mondialisée » et « fragilisée »
}

\section{Georges Daniel Véronique}

\section{(2) OpenEdition \\ Journals}

\section{Édition électronique}

URL : https://journals.openedition.org/rdlc/8570

DOI : $10.4000 /$ rdlc. 8570

ISSN : 1958-5772

Éditeur

ACEDLE

\section{Référence électronique}

Georges Daniel Véronique, «Questions de socialisation et d'identité : l'appropriation des langues dans une Europe « mondialisée » et « fragilisée » », Recherches en didactique des langues et des cultures [En ligne], 18-1 | 2021, mis en ligne le 03 mai 2021, consulté le 03 août 2021. URL : http:// journals.openedition.org/rdlc/8570; DOI : https://doi.org/10.4000/rdlc.8570

Ce document a été généré automatiquement le 3 août 2021.

\section{cc) (†)}

Recherches en didactique des langues et des cultures is licensed under a Creative Commons AttributionNonCommercial-NoDerivatives 4.0 International License 


\title{
Questions de socialisation et d'identité : l'appropriation des langues dans une Europe « mondialisée » et « fragilisée »
}

\author{
Georges Daniel Véronique
}

1 Mon intervention portera sur les enjeux de socialisation et d'identité qui traversent les écosystèmes linguistiques des sociétés européennes "mondialisées ». Socialisation et appropriations langagières sont liées. Maîtriser des pratiques langagières et discursives permet d'agir en acteur de la société à laquelle on appartient, et produire des significations sociales, dont celles liées à l'identité. Dans une Europe « fragilisée » par la mondialisation, des tensions apparaissent autour des socialisations langagières et engagent des questions identitaires. Dans cette conjoncture, la recherche et l'intervention en didactique des langues (DDL) prône l'« enseignement plurilingue » et promeut l'interculturalité. La discussion critique de ces notions et pratiques, déjà entamée, doit être poursuivie. Il s'agit de comprendre si d'autres voies de conceptualisation et d'intervention peuvent être ouvertes.

2 Les contraintes linguistiques qu'imposent la mondialisation économique (la prééminence de l'anglais comme langue hyper-centrale, par exemple) et la circulation des personnes (les migrations internationales et les déplacements des ressortissants d'outre-mer vers la France, par exemple) vers l'Europe, ébranlent les écosystèmes linguistiques des sociétés européennes et leurs politiques linguistiques (éducatives) et sociales. À des gestions différenciées de leurs pluralités linguistiques internes, s'ajoutent, pour chacun des pays de l'UE, des obligations de formation des personnes parlant des langues non territoriales, venues d'ailleurs, obligations remplies de façon variable.

3 Les manifestations de ces tensions et de ces désarrois sont nombreuses. Au niveau de la DDL, on s'en tiendra aux questions d'appropriation linguistique dans leurs environnements socio-politiques. 
L'exemple français montre que les modes de socialisation (dans le système éducatif, dans les secteurs administratifs, dans les media etc.) qu'instaure la République française pour ses ressortissants et pour les étrangers qu'elle accueille, et les modes d'appropriation du français, des « langues de France » (langues régionales, langues non territoriales), des langues de l'Union Européenne, et des autres langues qu'elle propose, sont à interroger. Par exemple, le débat sur le «français langue d'intégration » doit être repris à nouveaux frais, quelques années après la polémique vécue lors de sa formulation initiale.

5 Dans son aménagement linguistique actuel, la France, qui a signé la Charte européenne des langues européennes ou minoritaires en prenant trente-neuf engagements, accorde le statut de «langue de France » à des langues non-territoriales comme le yiddish, le judéo-espagnol, le berbère et les arabes dialectaux, et aux langues des outre-mer. Les conséquences sociales, culturelles et éducatives de ces choix restent à explorer.

6 J'identifie au moins trois points de tension dans l'écosystème linguistique français :

7 i) La mondialisation économique favorise la diffusion de certaines langues centrales ou hyper-centrales, le chinois et l'anglais par exemple, mais la circulation des personnes renforce de fait le plurilinguisme dans la vie française. L'arrivée de nouvelles populations étrangères (les réfugiés et les demandeurs d'asile) éprouve les appareils éducatifs (étatiques et non étatiques) dans leurs activités d'enseignement de la langue française, voire des langues régionales, et dans leur prise en compte de la diversité linguistique.

8 ii) Dans sa gestion de l'identité française, l'état-nation occulte sa pluralité linguistique interne (langue de la République, langues territoriales de France et des Outre-Mer, langue de France non-territoriales etc.). La reconnaissance effective des langues parlées en France (au-delà des " langues de France ») semble difficile. On peut relever un déficit d'information sur la diversité des langues parlées en France, sur les conséquences bénéfiques de la pluralité linguistique, et sur les enjeux d'appropriation et de socialisation ainsi posés. Ces omissions accroissent les crispations identitaires (la peur de submersion culturelle, d'aliénation d'un patrimoine linguistique et culturel fantasmé, la peur de l'attrition des langues de France etc.).

9 iii) Les défis de l'illettrisme et les conséquences socio-politiques et économiques de cet état de fait (les enjeux de l'empowerment) ne sont guère posés en rapport avec la pluralité linguistique interne.

10 Lors du débat, je souhaite organiser mon propos autour des trois points suivants :

1. Quels sont les enjeux de socialisation liés à la langue française et aux «langues de France » dans les différentes sphères de la vie sociale en France métropolitaine et d'outremer (enseignement, vie culturelle, médias) ? Quelles fonctions pour quelles langues? Comment (re)construire ces appropriations linguistiques?

2. Comment mieux poser l'appropriation de la littéracie dans les langues de France et la question de la lutte contre l'illettrisme afin de promouvoir des valeurs démocratiques et l'empowerment?

3. La pratique $d u$ « français national » et des autres langues territoriales et non territoriales et la définition de soi et de ses groupes d'appartenance : quels enjeux identitaires? 


\section{AUTEUR}

\section{GEORGES DANIEL VÉRONIQUE}

Laboratoire Parole et Langage, UMR 7309 CNRS \& Aix-Marseille Université

Georges Daniel Véronique, né en 1948 (Port-Louis, Maurice), est professeur émérite de linguistique française et d'études créoles à l'Université d'Aix-Marseille. En poste de 2005 à 2016 dans cette université, il a été antérieurement professeur de linguistique et de didactique à l'université Paris III- Sorbonne Nouvelle (1994-2005). Ses travaux portent sur les langues en contact, l'acquisition des langues étrangères, les créoles français et la didactique des langues. Courriel : georges.veronique[at]orange.fr 